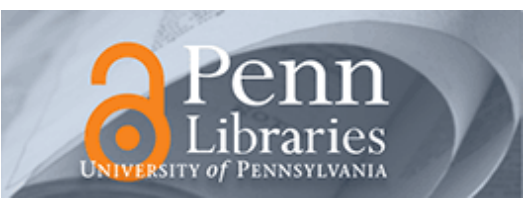

University of Pennsylvania

ScholarlyCommons

December 2005

\title{
Solution mediated effect of bioactive glass in poly (lactic-co- glycolic acid)-bioactive glass composites on osteogenesis of marrow stromal cells
}

Jun Yao

University of Pennsylvania

Shula Radin

University of Pennsylvania

Gwendolen Reilly

University of Pennsylvania

Phoebe S. Leboy

University of Pennsylvania

Paul Ducheyne

University of Pennsylvania, ducheyne@seas.upenn.edu

Follow this and additional works at: https://repository.upenn.edu/be_papers

\section{Recommended Citation}

Yao, J., Radin, S., Reilly, G., Leboy, P. S., \& Ducheyne, P. (2005). Solution mediated effect of bioactive glass in poly (lactic-co-glycolic acid)-bioactive glass composites on osteogenesis of marrow stromal cells. Retrieved from https://repository.upenn.edu/be_papers/67

Postprint version. "This is a preprint of an article published in Journal of Biomedical Materials Research Part $A$, Volume 75A, Issue 4, 15 December 2005, pages 794-801."

Publisher URL: http://dx.doi.org/10.1002/jbm.a.30494

This paper is posted at ScholarlyCommons. https://repository.upenn.edu/be_papers/67

For more information, please contact repository@pobox.upenn.edu. 


\title{
Solution mediated effect of bioactive glass in poly (lactic-co-glycolic acid)- bioactive glass composites on osteogenesis of marrow stromal cells
}

\author{
Abstract \\ A previous study demonstrated that the incorporation of bioactive glass (BG) into poly (lactic-co-glycolic \\ acid) (PLGA) can promote the osteoblastic differentiation of marrow stromal cells (MSC) on PLGA by \\ promote the formation of a calcium phosphate rich layer on its surface. To further understand the \\ mechanisms underlying the osteogenic effect of PLGA-BG composite scaffolds, we tested whether \\ solution-mediated factors derived from composite scaffolds/hybrids can promote osteogenesis of \\ marrow stromal cells. The dissolution product from PLGA-30\%BG scaffold stimulated osteogenesis of \\ MSC, as was confirmed by increased mRNA expression of osteoblastic markers such as osteocalcin \\ $(\mathrm{OCN})$, alkaline phosphatase (ALP), and bone sialoprotein (BSP). The three-dimensional structure of the \\ scaffolds may contribute to the production of cell derived factors which promoted distant MSC \\ differentiation. Thus PLGABG composites demonstrates significant potential as a bone replacement \\ material.

\section{Keywords} \\ poly (lactic-co-glycolic acid), bioactive glass, calcium phosphate, marrow stromal cells, osteogenesis

\section{Comments} \\ Postprint version. "This is a preprint of an article published in Journal of Biomedical Materials Research \\ Part A, Volume 75A, Issue 4, 15 December 2005, pages 794-801." \\ Publisher URL: http://dx.doi.org/10.1002/jbm.a.30494
}


Solution mediated effect of bioactive glass in poly (lactic-co-glycolic acid)bioactive glass composites on osteogenesis of marrow stromal cells

\begin{abstract}
A previous study demonstrated that the incorporation of bioactive glass (BG) into poly (lactic-co-glycolic acid) (PLGA) can promote the osteoblastic differentiation of marrow stromal cells (MSC) on PLGA by promote the formation of a calcium phosphate rich layer on its surface. To further understand the mechanisms underlying the osteogenic effect of PLGA-BG composite scaffolds, we tested whether solution-mediated factors derived from composite scaffolds/hybrids can promote osteogenesis of marrow stromal cells. The dissolution product from PLGA-30\%BG scaffold stimulated osteogenesis of MSC, as was confirmed by increased mRNA expression of osteoblastic markers such as osteocalcin (OCN), alkaline phosphatase (ALP), and bone sialoprotein (BSP). The three-dimensional structure of the scaffolds may contribute to the production of cell derived factors which promoted distant MSC differentiation. Thus PLGABG composites demonstrates significant potential as a bone replacement material.
\end{abstract}

Key words: poly (lactic-co-glycolic acid); bioactive glass; calcium phosphate; marrow stromal cells; osteogenesis 


\section{Introduction:}

It is generally required in bone remodeling and repair that new osteoblasts should be constantly produced from multipotential mesenchymal cells, which have the capacity to differentiate into a variety of cell types including osteoblasts $(1,2)$. In the tissue engineering approach to repair bone defects, a population of mesenchymal cells is cultured on the biomaterials substrate, some of which are already committed osteoprogenitors and others are still undifferentiated. Thus, mesenchymal cells challenge the implant materials with a complex task. The ideal implant materials are required not only to promote the further differentiation of committed osteoprogenitors, but also to induce the osteogenic commitment of undifferentiated cells.

Several recent studies have examined the proliferation and differentiation capacity of stem cells using rat marrow stromal cells (MSC) seeded on various materials with the potential to be used as implant materials (1-8). In a previous study, it has been shown that culturing rat MSC on poly (lactic-co-glycolic acid)bioactive glass composites (PLGA-BG) increases osteogenic differentiation (9). Thus, a major objective of the experiments described in the present study is to probe the mechanism by which PLGA-BG composites promote the osteogenic commitment and differentiation of multipotential MSC. Therefore, this study will 
use primary MSC rather than bone-derived osteoblasts or osteoprogenitor cell lines.

It has been reported that there is considerable species variation among mammalian MSC with regard to their ability to undergo osteogenesis (11-13) This species variation includes differences in growth factor requirements, osteogenic capacity, and the response to osteogenic stimuli (11-13). Since rat has been widely used as animal model to study the osteogenesis of MSC, rat MSC was used in this study. To examine the species variation in response to stimuli in vitro, the behavior of rat MSC was compared with that of human MSC.

The starting point of the study is the observation that MSC present on the tissue culture plastic surrounding the dense BG discs were producing significantly more alkaline phosphatase (ALP) than distant cells (14). Moreover, it was found that this observation was independent of inducers, suggesting that BG constituents may contribute to the increased production of ALP (14).

In a study in which human osteoblast-like cells were cultured on a silicon containing compound zeolite $A$, it was found that the increase of cell DNA synthesis and ALP activity was dose dependent. The authors proposed that it was due to the dissolution products of zeolite A (15). Other experiments with ROS cells showed that cells surrounding porous bioactive glass disks had higher alkaline phosphatase activities than untreated controls $(16,17)$. 
These observations form the basis for the present study on the solutionmediated effect of PLGA-30\%BG composite on MSC described here. The major focus in this study is to test whether incorporation of the BG into PLGA will lead to the solution-mediated effects on osteogenic commitment of MSC. Furthermore, it is the goal to examine the mechanisms underlying the solutionmediated effects of the BG.

\section{Methods and materials:}

\section{Formulation of polymer/ceramic composites}

PLGA-30\%BG microspheres were produced by emulsification as described in a previous study (8,18,19). Briefly, 65-35 PLGA (MW: 100K, Medisorb) was dissolved in methylene chloride $\left(\mathrm{CHCl}_{3}\right)$, and then 30 weight\% BG $45 \mathrm{~S} 5$ powder $\left(45 \% \mathrm{SiO}_{2}, 24.5 \% \mathrm{CaO}, 24.5 \% \mathrm{Na}_{2} \mathrm{O}\right.$, and $6 \% \mathrm{P}_{2} \mathrm{O}_{5}$ by weight) (< $40 \mu \mathrm{m}$ particle size) was added to the solution. This mixture was added dropwise to a stirred poly (vinyl alcohol) (PVA) solution. Microspheres were isolated by filtration, washed with deionized water, air dried and then vacuum dried. Dried particles were sieved using a nylon mesh. The PLGA-30\%BG microspheres of a specific size range (350 to $500 \mu \mathrm{m}$ ) were poured into a $12 \mathrm{~mm}$ diameter Teflon mold and heated at $65^{\circ} \mathrm{C}$ for 4 hours to produce a porous scaffold.

\section{$\underline{\text { Rat MSC cultures }}$}


Rat marrow cells from femora of 4-week female Wistar rats were isolated as previously described (20). The mononuclear cells were centrifuged, washed in Hanks' balanced salt solution (HBSS), counted and plated at $1-2 \times 10^{5} / \mathrm{cm}^{2}$ in $\alpha$ MEM medium supplemented with $10 \%$ fetal calf serum, 100 units $/ \mathrm{ml}$ penicillin/streptomycin and maintained at $37^{\circ} \mathrm{C}$ in $5 \% \mathrm{CO}_{2}, 95 \%$ air. After 4 days of primary culture, the confluent cells were harvested and re-suspended in culture media to seed on porous substrates.

\section{Cell culture on or surrounding porous scaffolds}

After sterilization with ethanol and ultraviolet light, PLGA-30\%BG scaffold samples were placed into sterile 12-well tissue culture plastic dishes. MSC suspensions were injected into the scaffolds at a density of $5 \times 10^{4}$ cells/sample. In order to promote attachment, cells were allowed to adhere to the scaffold for $30 \mathrm{~min}$ prior to the addition of $6 \mathrm{ml}$ media. Some of the cells penetrated the scaffold and attached to the tissue culture plastic dishes. In this paper, the cells physically located on the tissue culture plastic around the scaffolds are denoted as "surrounding cells" (Figure 1). Cells were cultured under humidified conditions, at $37^{\circ} \mathrm{C}$ and $5 \% \mathrm{CO}_{2}$ for periods up to 9 days. The cell culture medium was changed every two days and contained $100 \mu \mathrm{g} / \mathrm{ml}$ ascorbic acid and $10^{-7} \mathrm{M}$ dexamethasone (Dex). The control group consisted of cells cultured in a PLGA scaffold. As the primary osteoblast differentiation marker we quantified ALP activity as previously described (20) for both cells in the scaffolds as well as cells surrounding the scaffolds. The surrounding cells harvested at day 7 were 
further assayed for the mRNA expression of ALP and other osteoblast maturation markers such as osteocalcin (OCN), osteopontin (OPN), and bone sialoprotein (BSP).

Solution mediated effects of scaffolds on rat MSC

We physically separated cells from PLGA-30\%BG scaffolds by using permeable membranes (Falcon cell culture inserts), as is shown in figure 2. The scaffold with cells was denominated as " seeded scaffold ". Rat MSC were cultured in plastic wells in the presence of, but physically separated from, PLGA$30 \%$ BG scaffolds with and without seeded cells. The rat MSC cultured on the plastic wells were denominated as "distant cells". The ability of distant cells to undergo differentiation was tested without osteogenic inducers and with dexamethasone. The ALP activities of the distant cells were measured after 9 days. Cells that showed elevated ALP activity were further assayed for the mRNA expression of ALP and other osteoblast maturation markers such as osteocalcin (OCN) and bone sialoprotein (BSP). The negative controls for each experiment were rat MSC cultured in tissue culture wells containing membranes and seeded and unseeded PLGA scaffolds (Figure 2).

Comparison of the response to PLGA-30\%BG composites on the surrounding rat and human MSC

Human and rat MSC were compared for their ability to respond to BG in 
the absence of exogenous BMP. Human MSC were cultured in PLGA-30\%BG scaffolds at a density of 200,000 cells/sample and some of them grew on the tissue culture plastic dishes around the scaffolds as shown in figure 1. The effect of the seeded scaffolds on the surrounding cells was examined initially by removing the seeded scaffolds at the end of culture and measuring the ALP activity for cells on tissue culture wells.

\section{Measurement of mRNA levels}

Further analyses of osteogenesis were done by measuring mRNA levels of several osteoblast maturation markers, using realtime RT-PCR. Cell samples were lysed directly in TRI reagent (Molec Res Ctr) and total RNA in the aqueous phase was precipitated with isopropanol. The RNA pellet was resuspended in DEPC-treated water and quantitated spectrophotometrically. $2 \mu \mathrm{g}$ aliquots of RNA were then reverse transcribed to cDNA using a First Strand Synthesis system (Invitrogen) with oligo(dT) as primer. Measured amounts $(2.5 \mu \mathrm{l})$ of the cDNA products were added to a Fast-Start PCR reaction mix containing SybrGreen (Roche) along with primer pairs specific for each marker, and the reaction was carried out using a Cephiad SmartCycler thermocycler. This real-time PCR technology reported the PCR cycle number at which the level of double stranded product increased SybrGreen fluorescence above threshold values (crossing points). The crossing points were then used to calculate relative amount of mRNA in arbitrary units. The following primer pairs specific for rat osteoblast markers were used: 


\begin{tabular}{|l|l|l|l|}
\hline \multicolumn{1}{|c|}{ Gene } & \multicolumn{1}{|c|}{ Forward Primer } & \multicolumn{1}{c|}{ Reverse Primer } & Genbank ID \\
\hline $\begin{array}{l}\text { Alkaline } \\
\text { phosphatase }\end{array}$ & $\begin{array}{l}\text { 5'TTTGCTACCTGCC } \\
\text { TCACTTCCG }\end{array}$ & $\begin{array}{l}\text { 5'GGCTGTGACTAT } \\
\text { GGGACCCAG }\end{array}$ & gi 7106245 \\
\hline Osteopontin & $\begin{array}{l}\text { 5'TTCCAAGCAACTC } \\
\text { CAATGAAAG }\end{array}$ & $\begin{array}{l}\text { 5'ACCTTGATAGCCT } \\
\text { CATCGGAC }\end{array}$ & gi 6981579 \\
\hline Osteocalcin & $\begin{array}{l}\text { 5'TGACTGCATTCTG } \\
\text { CCTCTCTG }\end{array}$ & $\begin{array}{l}\text { 5'GCTGTGCCGTCC } \\
\text { ATACTTTCG }\end{array}$ & gi 576530 \\
\hline $\begin{array}{l}\text { Bone } \\
\text { sialoprotein }\end{array}$ & $\begin{array}{l}\text { 5'ACAGCTGACGCG } \\
\text { GGAAAGTTG }\end{array}$ & $\begin{array}{l}\text { 5'ACCTGCTCATTTT } \\
\text { CATCCACTTC }\end{array}$ & gi 205861 \\
\hline
\end{tabular}

All ALP activity measurements were made in triplicate and expressed as means \pm standard deviations. The results of experiments using at least 3 independent primary cell preparations were averaged.

\section{Results}

To quantify the effect of incorporating BG into PLGA on the osteogenic differentiation of marrow stromal cells, we kinetically assayed the alkaline phosphatase activity of cells cultured on porous scaffolds as a function of time for 5, 7 and 9 days with and without the exogenous inducer, Dex. These results are shown in figure 3. Cells cultured on the scaffold of PLGA-30\%BG expressed an elevated alkaline phosphatase activity in comparison to those on PLGA. In the 
presence of Dex, the alkaline phosphatase activity on PLGA-30\%BG was also significantly higher than on PLGA alone.

With or without Dex, cells placed on tissue culture plastic wells around the PLGA-30\%BG scaffolds expressed a higher ALP level than those around PLGA scaffolds (Figure 4). The analysis of gene expression of ALP, OPN, OCN and BSP using realtime PCR confirmed the above observations (Figure 5). In the presence of Dex, the cells nearby the PLGA-30\%BG scaffolds showed the highest mRNA expression for all osteogenic markers. Furthermore, in the absence of Dex, the cells around PLGA-30\%BG scaffolds expressed significantly higher levels of ALP, OPN, OCN, and BSP than those surrounding PLGA scaffolds. This suggests that the elevated levels of mRNA expression may be partially attributed to dissolved components of the BG content in composite scaffolds.

The cell culture medium exposed to the isolated PLGA-30\%BG scaffolds alone promoted the osteogenesis of the distant cells on the tissue culture plastic wells (Figure 6). This suggests that either glass dissolution product is responsible for the osteogenesis or that molecules in solution have been activated by contact with the glass derived surface reaction layer on the composites. In the presence of PLGA-30\%BG scaffolds seeded with cells, the distant cells on culture plastic wells expressed the higher level of alkaline phosphatase activity. This suggests that either cellular contact with the scaffold enhanced the concentration of glass 
dissolution product in the medium or soluble factors derived from cells that adhere to the scaffold contributed to stimulating the osteogenesis of the distant cells.

To confirm the effect of solution mediated factors associated with the presence of BG in PLGA-30\%BG scaffold on the osteogenic differentiation of marrow stromal cells, we analyzed the gene expression of ALP, OCN and bone BSP using realtime PCR. The mRNA gene expression results are shown in figure 7. MSC cultured in the plastic wells with medium conditioned by PLGA-30\%BG scaffolds expressed a higher mRNA expression of all markers than cells exposed to medium conditioned by PLGA alone. Furthermore, mRNA expression of ALP, OCN and BSP was found at least doubled for the distant cells on the plastic in medium conditioned by cell-seeded PLGA-30\%BG scaffold compared to medium conditioned by cell-seeded PLGA scaffold (figure 7). However, D-PLGA-cells values are constantly higher than D-PLGA, suggesting somehow the effect has nothing to do with $B G$.

Human MSC do not undergo osteogenesis in response to BMPs (13) and therefore a comparison of rat vs. human MSC should provide a rapid indication of whether BMPs mediate the glass associated effect on osteogenesis. The osteogenesis of human MSC on tissue culture plastic wells surrounding either PLGA-30\%BG or PLGA scaffolds was studied (figure 8). While rat MSC cultured with Dex showed a 4-6 fold higher level of ALP activity on PLGA-30BG than on 
PLGA. ALP activity of human MSC was not significantly different on PLGA and PLGA-30BG (figure 3 and figure 9a). Similarly, for cells cultured surrounding the scaffolds, ALP activity of rat MSC surrounding PLGA-30BG was approximately double that of cells surrounding PLGA alone (figure 4), while human MSC showed no significantly effect of PLGA-30BG as PLGA alone (figure 8b).

\section{Discussion}

Our studies focus on the molecular mechanisms underlying the effects of PLGA-BG composites on the osteogenic commitment of MSC. In previous studies, we demonstrated that the incorporation of BG powder into PLGA microspheres produced a composite that is osteogenic. While the previous studies concentrated on surface-mediated effects, this study examined potential solution-mediated effects of PLGA/BG composite.

Based on the previous data suggesting that cells cultured nearby but not on BG discs showed increased alkaline phosphatase activity (14), we tested whether PLGA-BG scaffolds could induce the osteoblastic differentiation of MSC cultured around scaffolds by examining ALP, OPN, OCN, and BSP expression. We found that the MSC surrounding seeded PLGA-30\%BG scaffolds expressed a higher level of alkaline phosphatase than those surrounding seeded PLGA scaffolds at day 7 and 9. It is plausible that ions such as $\mathrm{Ca}, \mathrm{PO}_{4}$ or $\mathrm{Si}$ released from the BG in PLGA-30\%BG scaffolds can influence osteogenesis. One alternative possibility is that osteogenic factors produced by cells that adhere to 
the PLGA-BG scaffold diffuse into the cell culture medium and affect the differentiation of cells present on the plastic well. One set of candidates for osteogenic factors are BMPs, which are known to be produced by MSC $(21,22)$. It should be noted that, while our studies examine two quite different potential mechanisms for osteoinductive effects, these two mechanisms need not be mutually exclusive. Since one portion of the surrounding cells were in direct contact with scaffold, we could not exclude the possibility that the higher level of ALP was partially due to the direct effect of PLGA-30\%BG composite on which a Ca-P rich layer formed. Thus, we cannot totally exclude surface-mediated effects from solution-mediated effect of PLGA/BG composites in this study.

Real-time PCR analysis revealed that, after 7 day of culture, cells on BG composite scaffolds expressed a higher level of ALP, OPN, OCN, and BSP mRNA messages compared with those on PLGA scaffolds (Figure 3). ALP is a cell-linked polypeptide that can remove nucleation inhibitors and the level of ALP activity indicates the stage of osteoblastic differentiation (23). The higher ALP expression on BG composite culture at day 7 suggests that $B G$ promotes osteoblastic differentiation. Osteopontin is thought to be responsible for cell attachment at a bone remodelling site and for regulation of crystal formation and growth because of its ability to bind HA (24). Osteocalcin is a calcium binding protein, which is synthesized by the osteoblast and secreted into the matrix at the time of bone mineralisation $(24,25)$. BSP is unique to mineralized tissues. It is expressed in osteoblasts and associates with the osteoid matrix, BSP is a good 
marker for osteoblastic differentiation (26). Thus, a high expression of ALP, OPN, $\mathrm{OCN}$, and BSP in cells suggests that BG promote osteogenic differentiation and mineralized tissue formation, resulting in rapid bone bonding.

We knew that rat MSC cultured surrounding the seeded PLGA-30\%BG scaffolds showed on elevated ALP, but couldn't confirm whether the BG-derived components were responsible (Figure 4). In order to exclude any direct surfacemediated effects of scaffolds on ALP activity and osteogenesis, we physically separated cells from PLGA-30\%BG scaffolds using permeable membranes, as shown in figure 2. These membranes allowed the ions penetrate but prohibited the cells and microspheres going through. The ability of rat MSC to undergo differentiation was tested in the presence of Dex. The result that the distant cells in presence of PLGA-30\%BG scaffolds expressed a higher level of alkaline phosphatase activity than with PLGA scaffolds suggested that soluble factors promote osteogenesis and that direct cell contact with the surface coating was not required for osteogenesis. Since there were no cells cultured in these scaffolds, we could rule out the possibility that the soluble factors were produced from the interaction between cells and scaffolds. Our previous study demonstrated that the BG 45S5 stimulated the osteogenic differentiation of MSC by the Ca-P rich layer that found on its surface $(6,7)$. Here we showed that the dissolution products derived from BG component in PLGA-30\%BG composites alone increased the expression of the osteoblastic phenotypic marker ALP. 
Are there any soluble factors derived from the cells adhering to scaffolds, which can stimulate the osteogenic differentiation of the distant MSC? To answer this question, we assayed the ALP activity of the distant cell cultured on plastic wells. These distant cells were physically separated from cell-seeded scaffolds (Figure 2). The result, that distant cells in the medium conditioned by the cellseeded scaffold expressed a higher level of ALP activity than those in the medium conditioned by the unseeded scaffold alone, indicates the elevated osteogenic differentiation of distant cells is related to having cells adhering to the scaffold (Figure 6). In controls, the distant cells in presence of the seeded PLGA scaffold also demonstrated a higher ALP activity than the unseeded PLGA scaffold, suggesting that the increased ALP activity is independent of a BG component in the scaffold. Thus, the possibility that cellular contact with the scaffold enhances the concentration of a BG dissolution product in the medium was ruled out. Instead, the results suggest that soluble factors produced by seeded cells on either PLGA or PLGA-30BG scaffolds stimulate the osteogenesis of the distant cells.

It is possible that the three dimensional structure of scaffolds contributed to stimulating seeded cells on scaffolds to produce soluble osteogenic factors, which diffused into the medium and promoted the osteogenic commitment of distant MSC on plastic wells. Since cells within tissue encounter a complex chemical and physical environment that is very different from common cell 
culture conditions, previous investigators have used three-dimensional cell culture methods to better simulate the physical environment of tissue $(27,28)$. In this study, when cells were cultured in porous three dimensional scaffolds, the scaffolds provided a structural support for MSC and the physical dimensions of the scaffold could influence cell attachment, proliferation, and differentiation. Thus the three dimensional structure of both PLGA and PLGA-30\%BG scaffolds may promote the seeded cells on scaffolds to produce osteogenic factors, which stimulate the expression of ALP. In the presence of the seeded PLGA-30\%BG scaffold, BG dissolution products in concert with the osteogenic factors derived from cells adhering to scaffolds further promoted the osteogenesis of the distant MSC. The distant cells that showed elevated expression of ALP activity were further assayed for expression of osteoblast maturation markers such as OCN, and BSP. The mRNA expression results of osteogenic markers further confirmed the osteogenesis of MSC.

On the assumption that some cell-derived soluble factors are partially responsible for induced osteogenesis, the most likely candidate is BMPs produced by the cells. Rat MSC produce considerable quantities of BMPs, which could promote the ostogenesis of rat MSC (29-31). However, BMP have been demonstrated to be a poor osteogenic inducer for human MSC in previous studies $(32,33)$. If BMP produced by seeded cells on scaffolds is primarily responsible for activating osteogenesis in rat MSC, we anticipated that human MSC should not show the same response as rat MSC. When human and rat 
MSC were compared for their ability to respond to PLGA-30\%BG scaffold in the absence of exogenous BMP, the results demonstrated that human MSC, unlike rat MSC, did not show significantly increased ALP activities in response to PLGA-30\%BG scaffold. These data suggest that BMPs are plausible candidates for cell-derived soluble factors that mediate the glass-associated effect on osteogenesis of rat MSC.

\section{Conclusion}

It was demonstrated that porous PLGA-30\%BG composites promote osteogenic commitment of MSC through solution-mediated factors. The dissolution product from BG components in the scaffold, in concert with the three-dimensional structure of scaffold, contributes to the solution-mediated effect on osteogenesis of MSC. This followed from the increased mRNA expression of osteogenic markers such as ALP, OCN, and BSP. The phenomenon that human MSC did not show the same response to PLGA$30 \% \mathrm{BG}$ scaffolds as rat MSC further suggests that BMPs is one of the possible set of molecules that are cells-derived and produce a BG derived solution mediated effect.

\section{Acknowledgement}

This work was supported by NIH grants DE13051 and DE 13800 


\section{References}

1. Ishaug SL, Crane GM, Miller MJ, Yasko AW, Yaszemski MJ, Mikos AG. Bone formation by three-dimensional stromal osteoblast culture in biodegradable polymer scaffolds. J Biomed Mater Res 1997; 36(1): 17-28.

2. Ozawa S, Kasugai S. Evaluation of implant materials (hydroxyapatite, glassceramics, titanium) in rat bone marrow stromal cell culture. Biomaterials 1996; 17(1): 23-9.

3. Ohgushi H, Dohi Y, Yoshikawa T, Tamai S, Tabata S, Okunaga K, Shibuya T. Osteogenic differentiation of cultured marrow stromal stem cells on the surface of BG ceramics. J Biomed Mater Res 1996; 32(3): 341-348.

4. Haynesworth SE, Goshima J, Goldberg VM, Caplan Al. Characterization of cells with osteogenic potential from human marrow. Bone 1992; 13: 81-88

5. Thompson GJ, Pleo DA. Ti-6A1-4V ion solution inhibition of osteogenic cell phenotype as a function of differentiation timecourse in vitro. Biomaterials 1996; 17(20): 1949-1954.

6. Qiu Q, Sayer M, Kawaja M, Shen X, Dvies JE. Attachment, morphology, and protein expression of rat marrow stromal cells cultured on charged substrate surfaces. J Biomed Mater Res 1998; 42(1): 117-127

7. Yoshikawa T, Ohgushi H, Dohi Y, Davies JE. Viable bone formation in porous hydroxyapatite: marrow cell-derived in vitro bone on the surface of ceramics. Biomedical Materials \& Engineering 1997; 7(1): 49-58

8. Laczka-Osyczka A, Laczka M, Kasugai S, Ohya K. Behavior of bone marrow cells cultured on three different coatings of gel-derived bioactive glassceramics at early stages of cell differentiation. J Biomed Mater Res 1998; 42(3): 433-42.

9. Yao J, Radin S, Leboy PS, Ducheyne P. The effect of BG content on synthesis and bioactivity of composite PLGA/BG substrate for tissue engineering. $29^{\text {th }}$ Annual Meeting of SFB, 2003

10. Kuznetsov SA, Robey PG. Species differences in growth requirements for bone marrow stromal fibroblast colony formation in vitro. Calcified Tissue International 1996; 59(4): 265-270

11. Krebsbach PH, Kuznetsov SA, Satomura K, Emmons RVB, Rowe DW, Robey $P G$. Bone formation in vivo: Comparison of osteogenesis by transplanted mouse and human marrow stromal fibroblasts. Transplantation 1997; 63(8): 1059-1069

12. Krebsbach PH, Kuznetsov SA, Bianco P, Robey PG. Bone marrow stromal cells: Characterization and clinical application. Critical Review in Oral Biology and Medicine 1999; 1(2): 165-181

13. Diefenderfer DL, Osyczka AM, Garino JP, Leboy PS. Regulation of BMPinduced transcription in cultured human bone marrow stromal cells. Journal of Bone \& Joint Surgery - American 2003;85(3): S19-S28

14. Baldick HL, Ducheyne P, Leboy PS. Bioactive glass increases alkaline phosphatase activity in rat marrow stromal cells in vitro. Fifth World Biomaterials Congress 1996. 
15. Keeting PE, Oursler MJ, Wiegand KE, Bonde SK, Spelsberg TC, Riggs BL. Zeolite A increases proliferation, differentiation, and transforming growth factor beta production in normal adult human osteoblast-like cells in vitro. $\mathrm{J}$ Bone Miner Res 1992; 7(11): 1281-9

16. Effah Kaufmann EA, Ducheyne P, Shapiro IM. Evaluation of osteoblast response to porous bioactive glass (45S5) substrates by RT-PCR analysis. Tissue Engineering 2000; 6(1): 19-28

17. Effah Kaufmann EA, Ducheyne P, Shapiro IM. Effect of varying physical properties of porous, surface modified bioactive glass $45 S 5$ on osteoblast proliferation and maturation. J Biomed Mater Res 2000; 52(4): 783-96

18. Elgendy HM, Norman ME, Keaton AR, Laurencin CT. Osteoblast-like cell (MC3T3-E1) proliferation on bioerodible polymers: an approach towards the development of a bone-bioerodible polymer composite material. Biomaterials 1993; 14: 263-269

19. Borden M, Attawia M, Khan Y, Laurencin CT. Tissue engineered microsphere-based matrices for bone repair: design and evaluation. Biomaterials 2002; 23(2):551-9

20. Leboy PS, Beresford JN, Devlin C, Owen ME. Dexamethasone induction of osteoblast mRNAs in rat marrow stromal cell cultures. J Cell Physiol 1991; 146: 370-78

21. Church VL, Harvey B, Ashton BA. Differential bone morphogenetic protein expression by pluripotent bone marrow stromal stem cells. Biochemical Society Transactions 1998; 26(1): S25-S25

22. Bi. LX, Simmons DL, Mainous E. Expression of BMP-2 by rat bone marrow stromal cells in culture. Calcified Tissue International 1999;64(1): 63-68.

23. Robey PG. The biochemistry of bone. Endocrinol Metab Clin North America 1989; 18: 859-902

24. Kasugai S, Nagata T, Sodek J. Temporal studies on the tissue compartmentalization of bone sialoprotein (BSP), osteopontin (OPN), and SPARC protein during bone formation in vitro. Journal of Cellular Physiology 1992; 152(3): 467-77

25. Hauschka PV, Wians FH. Osteocalcin-hydroxyapatite interaction in the extracellular organic matrix of bone. Anatomical Record 1989; 224(2): 180-8.

26. Hunter GK, Goldberg HA. Nucleation of hydroxyapatite by bone sialoprotein. Proc Natl Acad Sci USA 1993; 90(18): 8562-5

27. Casser-Bette M, Murray AB, Closs El, Erfle V, Schmidt J. Bone formation by osteoblast-like cells in a three-dimensional cell culture. Calcified Tissue International 1990; 46(1):46-56

28. Mehta S, Reed B, Antich P. Effects of high levels of fluoride on bone formation: an in vitro model system. Biomaterials 1995; 16(2):97-102

29. Church VL, Harvey B, Ashton BA. Differential bone morphogenetic protein expression by pluripotent bone marrow stromal stem cells. Biochemical Society Transactions 1998; 26(1): S25-S25

30. Kerrigan LA, Murphy JM, Bruder SP, Connolly TJ. BMP receptor expression in human mesenchymal stem cells. Transaction of the Orth Res Soc 1997; 22: 225 
31. Lianjia Y, Yan J. Immunohistochemical observations on bone morphogenetic protein in normal and abnormal conditions. Clin Orth 1990; 257: 249-256

32. Cheng SL, Yang JW, Rifas L, Zhang SF, Avioli LV. Differentiation of human bone marrow osteogenic stromal cells in vitro: induction of the osteoblast phenotype by dexamethasone. Endocrinology 1994; 134: 277-286

33. Lencanda F, Avioli LV, Cheng SL. Regulation of bone matrix protein expression and induction of differentiation of human osteoblasts and human bone marrow stromal cells by bone morphogenetic protein-2. Journal of Cellular Biochemistry 1997; 67(3): 386-398 


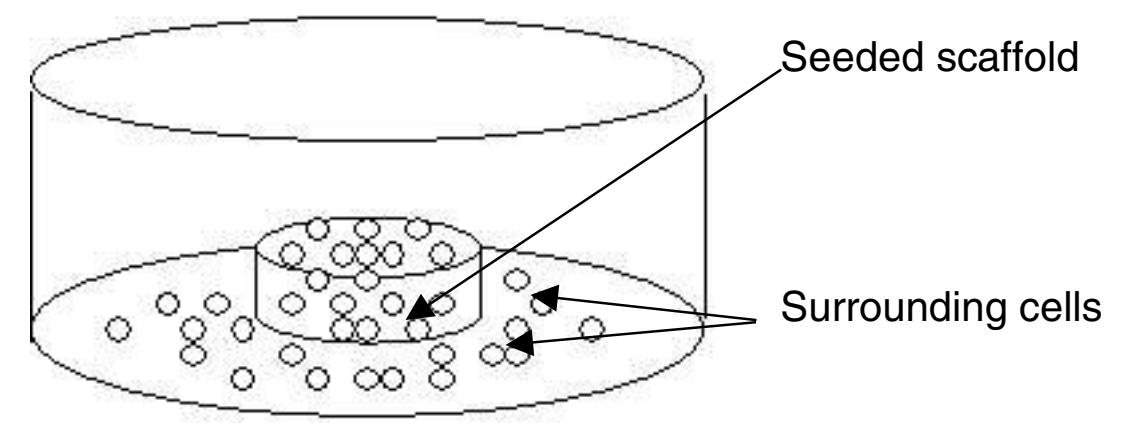

Figure 1: Rat marrow stromal cells cultured on or around the porous scaffolds

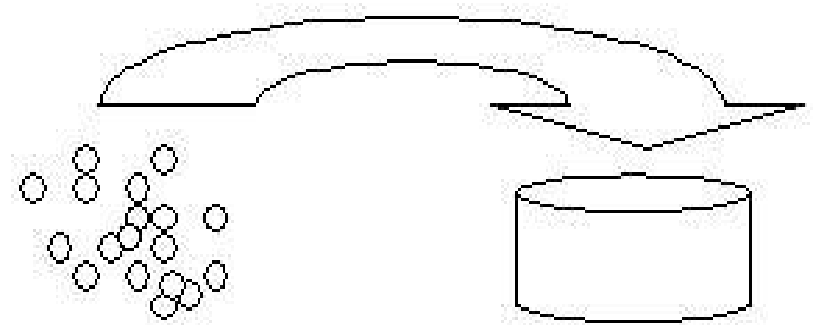

Cells

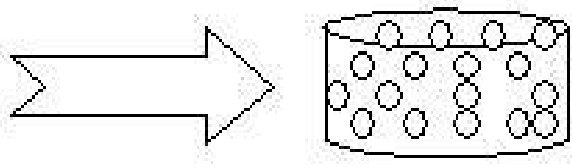

Seeded scaffold

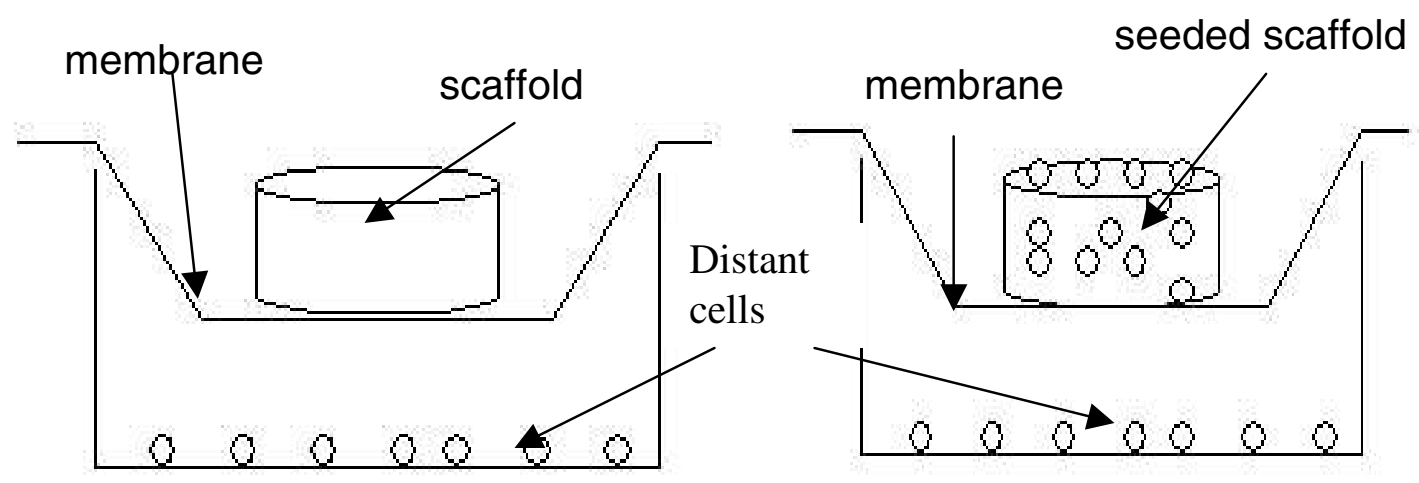

Figure 2: Cell culture system where cells are physically separated from PLGA$30 \%$ BG scaffold, which were either not seeded or seeded with cells. 


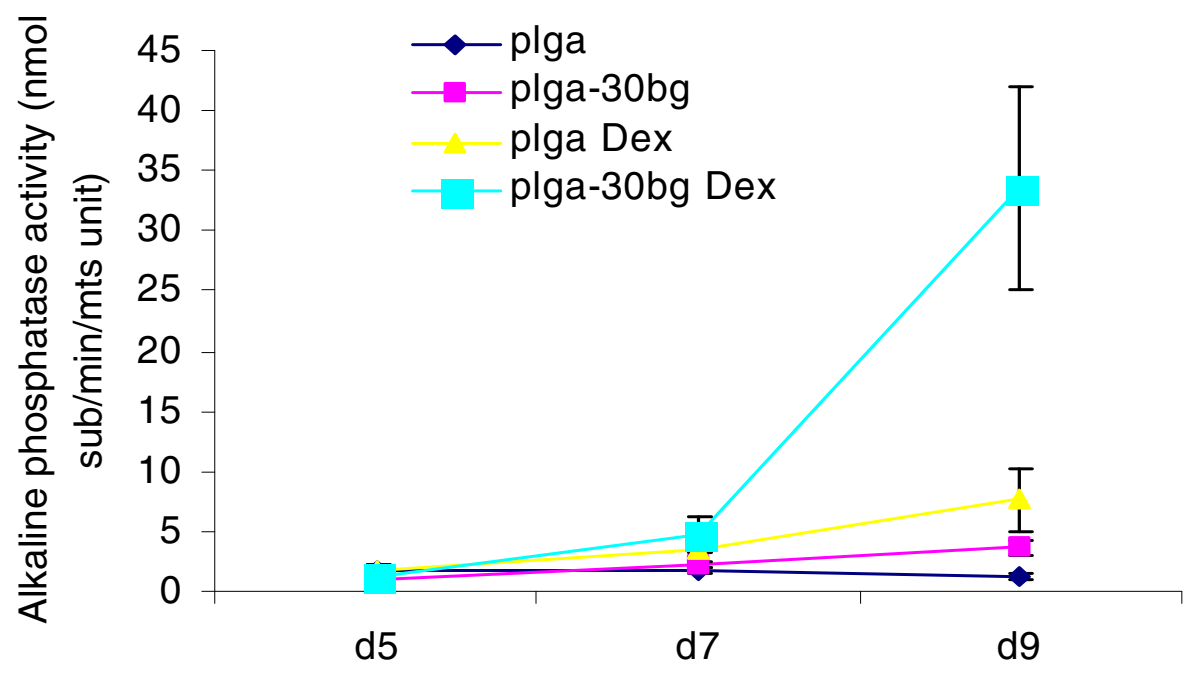

Figure 3: The activity of alkaline phosphatase as a function of time for rat marrow stromal cells cultured in porous PLGA scaffold or PLGA-30\%BG scaffold with/without $10 \mathrm{nM}$ Dex at 5,7,9 days.

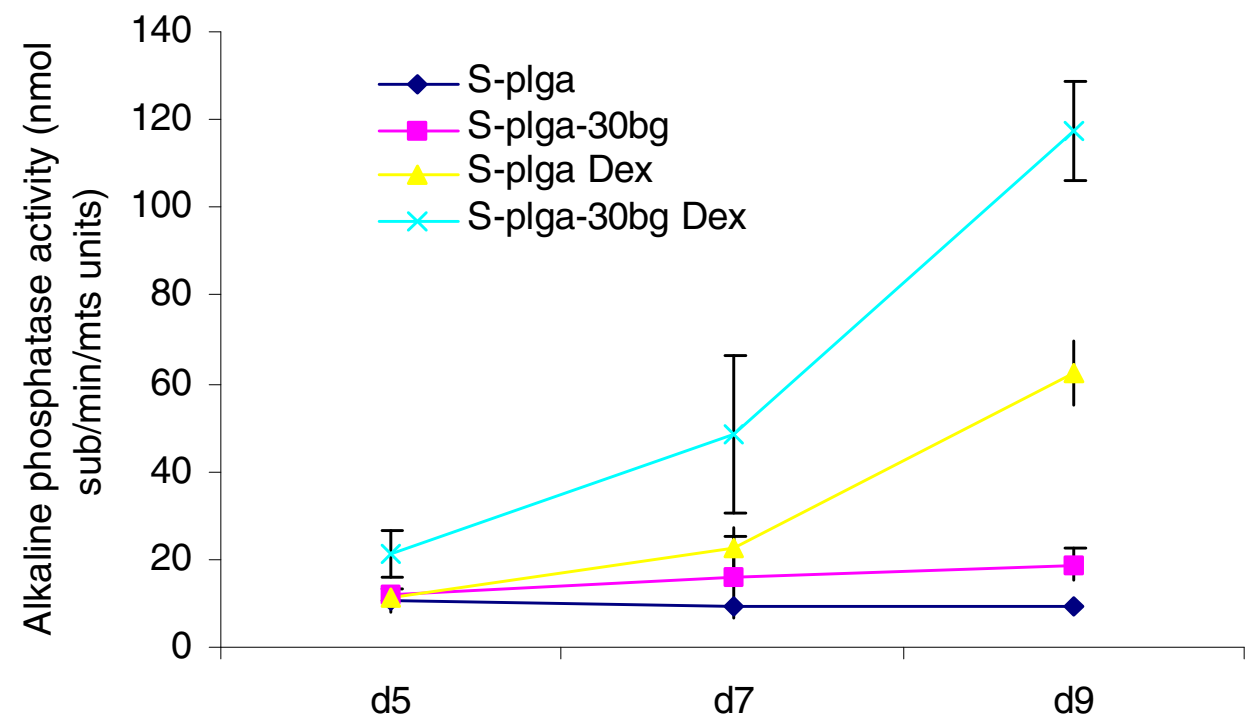

Figure 4: The activity of alkaline phosphatase as a function of time for rat marrow stromal cells cultured surrounding porous PLGA scaffold or PLGA-30\%BG scaffold with/without $10 \mathrm{nM}$ Dex at 5,7,9 days. S: Surrounding cells 

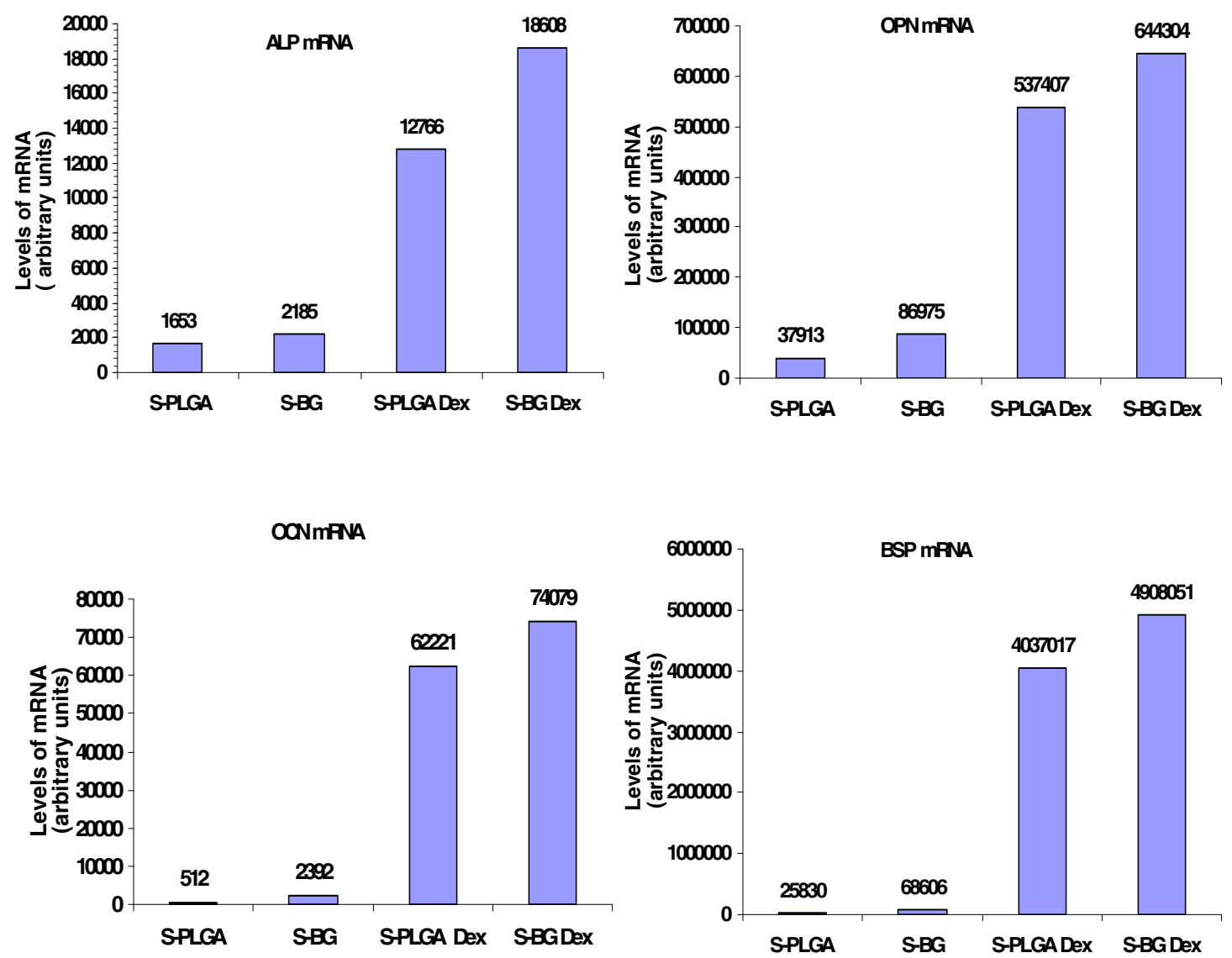

Figure 5: Gene expression of the osteogenic markers: alkaline phosphatase (ALP), osteopontin (OPN), osteocalcin (OCN) and bone sialoprotein (BSP) using realtime PCR. The sample mRNA was collected from rat marrow stromal cells cultured surrounding porous PLGA or PLGA-30\%BG scaffolds for 7 days. Dex = 10 nM. S: Surrounding cells. 


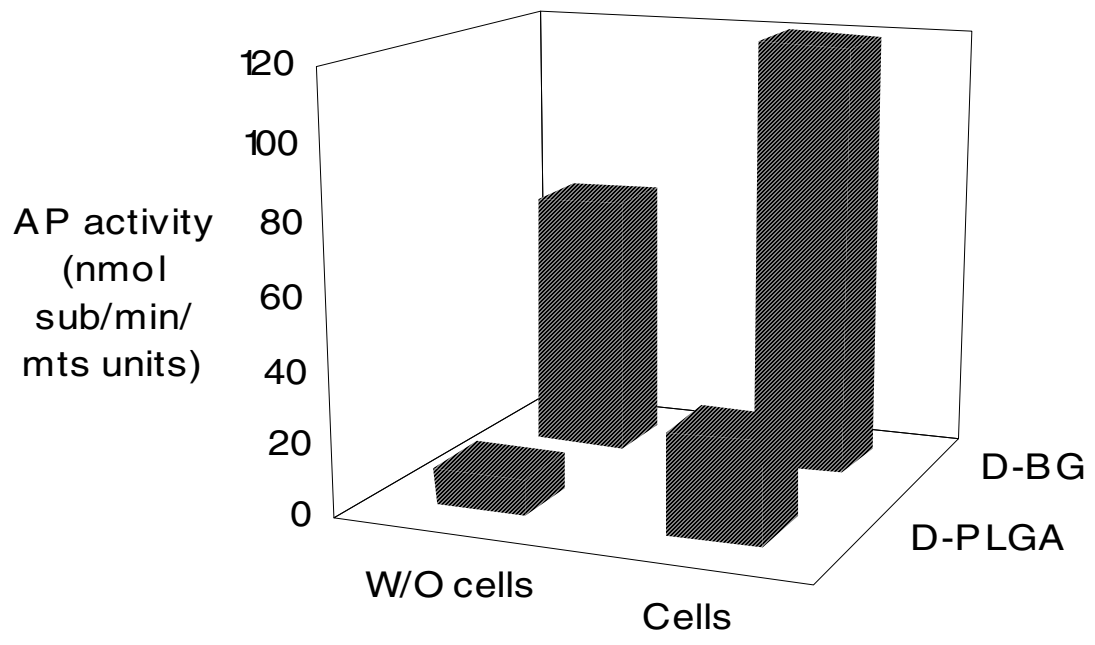

Figure 6: Osteogenesis of rat marrow stromal cells (Frozen cells) cultured for 9 days in culture wells. The cells were physically separated from the porous scaffolds by membranes. Scaffolds are seeded with cells or not. Dex $=10 \mathrm{nM}$. D: Distant cells, W/O: Without. 

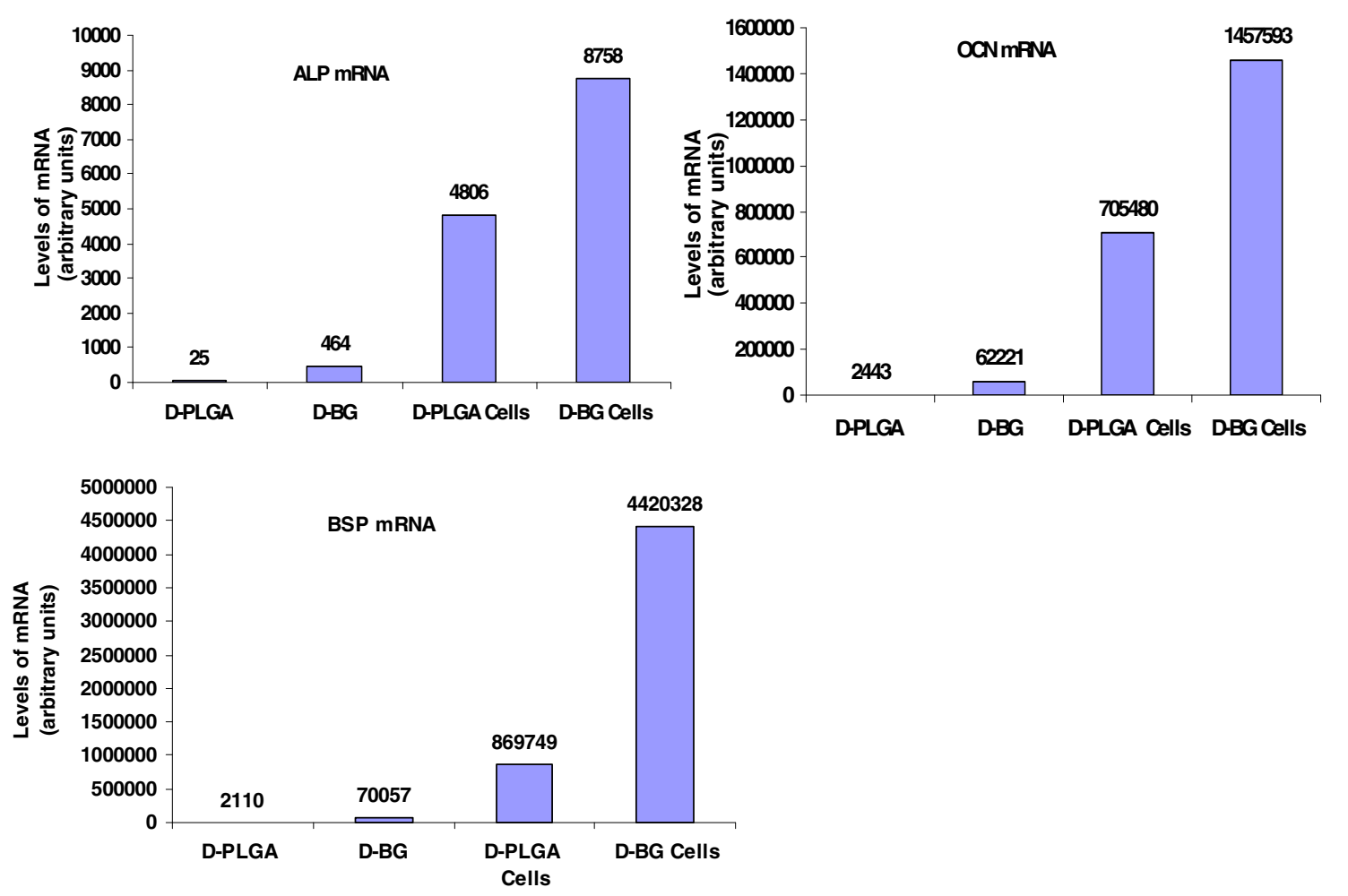

Figure 7: Gene expression of the osteogenic markers: alkaline phosphatase (ALP), osteocalcin (OCN) and bone sialoprotein (BSP) using realtime PCR. Cells are separated from PLGA or PLGA-30\%BG scaffolds by permeable membrane and cultured for 9 days. Dex=10 nM. D: Distant cells. 

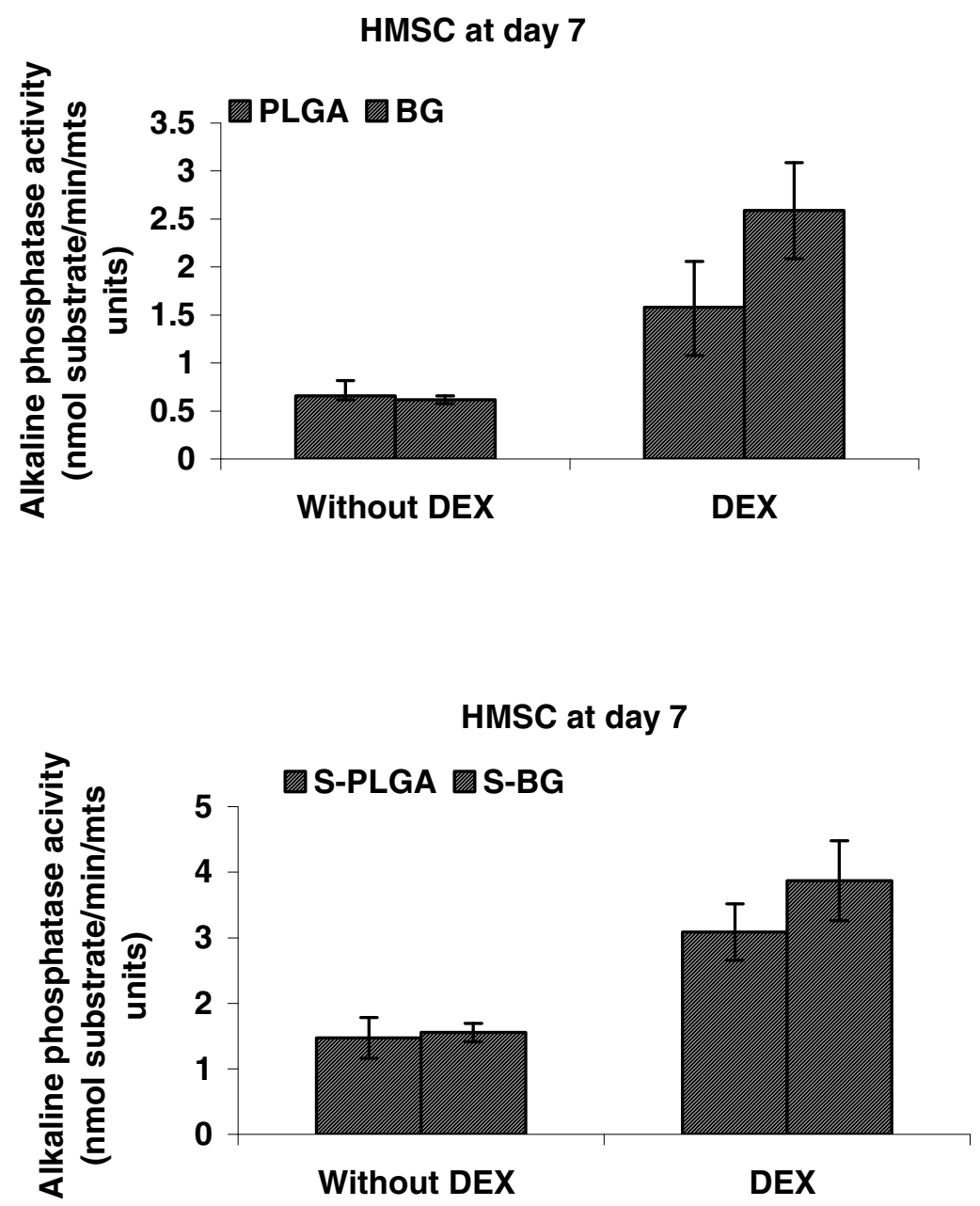

Figure 8: Osteogenesis of human marrow stromal cells (39 year old, male, passage 2) cultured on porous PLGA scaffold or PLGA-30\%BG scaffold for 7 days. $\operatorname{Dex}=10 \mathrm{nM}$ 


\section{Captions for all figures}

Figure 1: Rat marrow stromal cells cultured on or around the porous scaffolds

Figure 2: Cell culture system where cells are physically separated from PLGA$30 \%$ BG scaffold, which were either not seeded or seeded with cells.

Figure 3: The activity of alkaline phosphatase as a function of time for rat marrow stromal cells cultured in porous PLGA scaffold or PLGA-30\%BG scaffold with/without $10 \mathrm{nM}$ Dex at 5,7,9 days.

Figure 4: The activity of alkaline phosphatase as a function of time for rat marrow stromal cells cultured surrounding porous PLGA scaffold or PLGA-30\%BG scaffold with/without $10 \mathrm{nM}$ Dex at 5,7,9 days. S: Surrounding cells

Figure 5: Gene expression of the osteogenic markers: alkaline phosphatase (ALP), osteopontin (OPN), osteocalcin (OCN) and bone sialoprotein (BSP) using realtime PCR. The sample mRNA was collected from rat marrow stromal cells cultured surrounding porous PLGA or PLGA-30\%BG scaffolds for 7 days. Dex = $10 \mathrm{nM}$. S: Surrounding cells.

Figure 6: Osteogenesis of rat marrow stromal cells (Frozen cells) cultured for 9 days in culture wells. The cells were physically separated from the porous scaffolds by membranes. Scaffolds are seeded with cells or not. Dex $=10 \mathrm{nM}$. D: Distant cells, W/O: Without.

Figure 7: Gene expression of the osteogenic markers: alkaline phosphatase (ALP), osteocalcin (OCN) and bone sialoprotein (BSP) using realtime PCR. Cells are separated from PLGA or PLGA-30\%BG scaffolds by permeable membrane and cultured for 9 days. Dex=10 nM. D: Distant cells.

Figure 8: Osteogenesis of human marrow stromal cells (39 year old, male, passage 2) cultured on porous PLGA scaffold or PLGA-30\%BG scaffold for 7 days. $\operatorname{Dex}=10 \mathrm{nM}$ 